

\title{
EJERCICIO PLÁSTICO: El ayer y hoy del derrotero del Mural de David Alfaro Siqueiros
}

\author{
Rocío E. Trinidad Zapata \\ Investigadora Independiente \\ trini.trinita@gmail.com
}

\begin{abstract}
Resumen
Ejercicio Plástico, el Mural de David Alfaro Siqueiros, es conocido por ser la única obra de contenido no político del artista y por las circunstancias que rodearon su producción, olvido y rescate. No obstante, la relocalización de la pieza en el inaugurado Museo del Bicentenario por Cristina Fernández Kirchner, hoy renombrado como Museo de la Casa Rosada por la administración de Mauricio Macri, en su intento por despolitizar su contenido, le imprime un nuevo giro a la historia. La continuidad del mural en el museo, así como su interpretación actual no escapan del debate polarizado por la "grieta" que divide la sociedad argentina y que nos recuerda que lo cultural también es político. El artículo que presento ubica al mural en el contexto del museo en el que se encuentra--con sus cambios de nombre y contenido--, con el objetivo de explicar el proceso de politización-despolitización y el impacto que este ha producido en la interpretación del mural.
\end{abstract}

Palabras clave: David Alfaro Siqueiros, Ejercicio Plástico, Mural, Argentina

\begin{abstract}
Ejercicio Plástico, David Alfaro Siqueiros's mural, is known for being the only non-political work of the artist and for the circumstances surrounding his production, oblivion and rescue. Nevertheless, the relocation of the piece in the inaugurated Museo del Bicentenario by Cristina Fernández Kirchner, today renamed as Museo de la Casa Rosada by the administration of the president Mauricio Macri, in its attempt to depoliticize its contents, gives a new scope to history. The continuity of the mural in the museum, as well as its current interpretation, do not escape from a polarized debate due to the "gap" that divides Argentine society that reminds us that culture is also political. The article I present places the mural in the context of the museum in which it is located-with its changes of name and content -, with the objective to explain the process of politicization-depoliticization and the impact that this has produced in the interpretation of the mural.
\end{abstract}

Keywords: David Alfaro Siqueiros, Ejercicio Plástico, Mural, Argentina

\section{El Museo del Bicentenario}

El 24 de mayo del 2011, la entonces presidenta de la República Argentina Cristina Fernández de Kirchner inauguró el Museo del Bicentenario. Este se ubicó en la parte posterior de La Casa de Gobierno conocida como Casa Rosada, en el espacio en el que funcionara la Aduana Nueva, edificada por el arquitecto inglés Eduardo Taylor en 1855 (Casa Rosada, 2016). El proyecto del Museo fue ejecutado por el estudio de arquitectos B4FS, quienes en el 2006 se adjudicaron el primer premio del "Concurso Internacional de Anteproyectos para el Centro Cultural del Bicentenario (CCB) y de ideas para su entorno inmediato" convocado por el Ministerio de Planificación Federal, Inversión Pública y Servicios, la Secretaria de Cultura de la Nación y el Gobierno de la Ciudad Autónoma de Buenos Aires (García Zúñiga, 2015: 5). Este proyecto incluyó la restauración y la puesta en valor de los restos del edificio 
y las galerías subterráneas, la incorporación de espacios nuevos para instalar la sala de máquinas del Museo, el techado del Patio de Maniobras de la Aduana donde se situaría el Mural de David Alfaro Siquerios (García Zúñiga, 2015:8).

El objetivo del Museo del Bicentenario era recorrer, a través de su propuesta museográfica, tal como su nombre lo indicaba, los doscientos años de historia de la independencia de la República Argentina utilizando para ello recursos audiovisuales y objetos significativos: Algunos autos antiguos que movilizaron a presidentes, como el Gran Sport de 1954; retratos como el de Eva y Juan Domingo Perón realizado por Numa Ayrinha en 1948, que marcaron un hito al ser la primera vez que un presidente y la primera dama se retrataban juntos y sonriendo (Battistozzi, 1997); símbolos como el pañuelo ensangrentado de Hebe de Bonafini, una de las fundadoras de la Asociación Madres de la Plaza de Mayo; y recuerdos familiares de Cristina y Néstor Kirchner, sus fotografías matrimoniales hasta los mocasines y el lapicero Bic de Néstor, con el que, según dicen, firmaban las leyes, se dispusieron debajo de los arcos que circundaban el Patio de Maniobras del Museo. Fue justamente en ese espacio donde se colocó el Mural titulado Ejercicio Plástico, realizado en 1933 por el artista mexicano David Alfaro Siqueiros con la colaboración de los artistas argentinos Juan Carlos Castagnino, Antonio Berni, Lino Enea Spilimbergo y el artista uruguayo Enrique Lazaro en la localidad de Don Torcuato, perteneciente a la Provincia de Buenos Aires.

\section{La revolución del arte: Ejercicio Plástico}

David Alfaro Siqueiros (1896-1974), fue junto con Diego Rivera y José Clemente Orozco uno de los más grandes representantes del muralismo mexicano. Fue activo militante del Partido Comunista e interesado en vincular el arte con la realidad social. Arribó a Buenos Aires en 1933 y a través del escritor norteamericano Waldo Frank, quien intercedió con Victoria Ocampo, editora de la Revista Literaria Sur (Schavelzon, 2009), fue invitado a dictar una serie de conferencias en la Asociación Amigos del Arte, integrado por representantes de la elite, artistas y animadores culturales cuyo objetivo era "fomentar y facilitar la difusión" de las obras de los artistas, así como buscar el "bienestar material de los artistas argentinos” (Meo Laos, s.f:1). En Buenos Aires escribió artículos que vinculaban el arte y la revolución en el Diario Crítica de propiedad de Natalio Botana, estableció contactos con grupos de la izquierda local, en el ámbito político e intelectual "y dio conferencias que terminaron en sonados escándalos. En torno a él se producían disturbios en los que aprovechaba para marcar su línea política; era un movilizador nato" (Schávelzon, 2011:5).

Tuvo la intención de realizar murales públicos en la ciudad, pero no le fue posible dado el ambiente conservador porteño y la presencia de la Legión Cívica, órgano de represión de los grupos fascistas de derecha. Manteniendo en la mira su deseo de pintar aceptó la propuesta de Natalio Botana para intervenir el sótano de su quinta Los Granados. El sótano, era una gran cava, el espacio privado de Botana, donde departía con sus amigos. Puede resultar paradójico que, alguien como Siqueiros, militante, con ideales revolucionarios y claramente orientado hacia el arte público tuviera que aceptar la propuesta del acaudalado Botana para pintar un espacio particular. En términos prácticos para Siqueiros resultaba un ingreso económico que necesitaba. Pero, también resultaba un desafío por las dimensiones del espacio y la única alternativa posible para pintar a su alcance y para realizar de algún modo la revolución en el área que manejaba: el arte. Lo logró, componiendo una gran pintura dinámica: "Pintó las paredes, la bóveda y el piso del recinto semicilíndrico de poco menos de 150 metros cuadrados. La base de este mural envolvente, realizado en tres meses, mide 6.70 x 5.30 metros; las paredes tienen un metro y medio de altura, a partir de la cual se inicia la bóveda (medio cañón con una altura máxima de 2.93 metros)” (Schávelzon, 2009). Lo consiguió implementando una serie de novedades: Formó un grupo de trabajo con Castagnino, Berni, Enea Spilimbergo y Lazaro expresión de su propuesta de "trabajar en grupos socializados” (Schávelzon, 2011:8). Usó, aerógrafos a los que denominó "brocha 


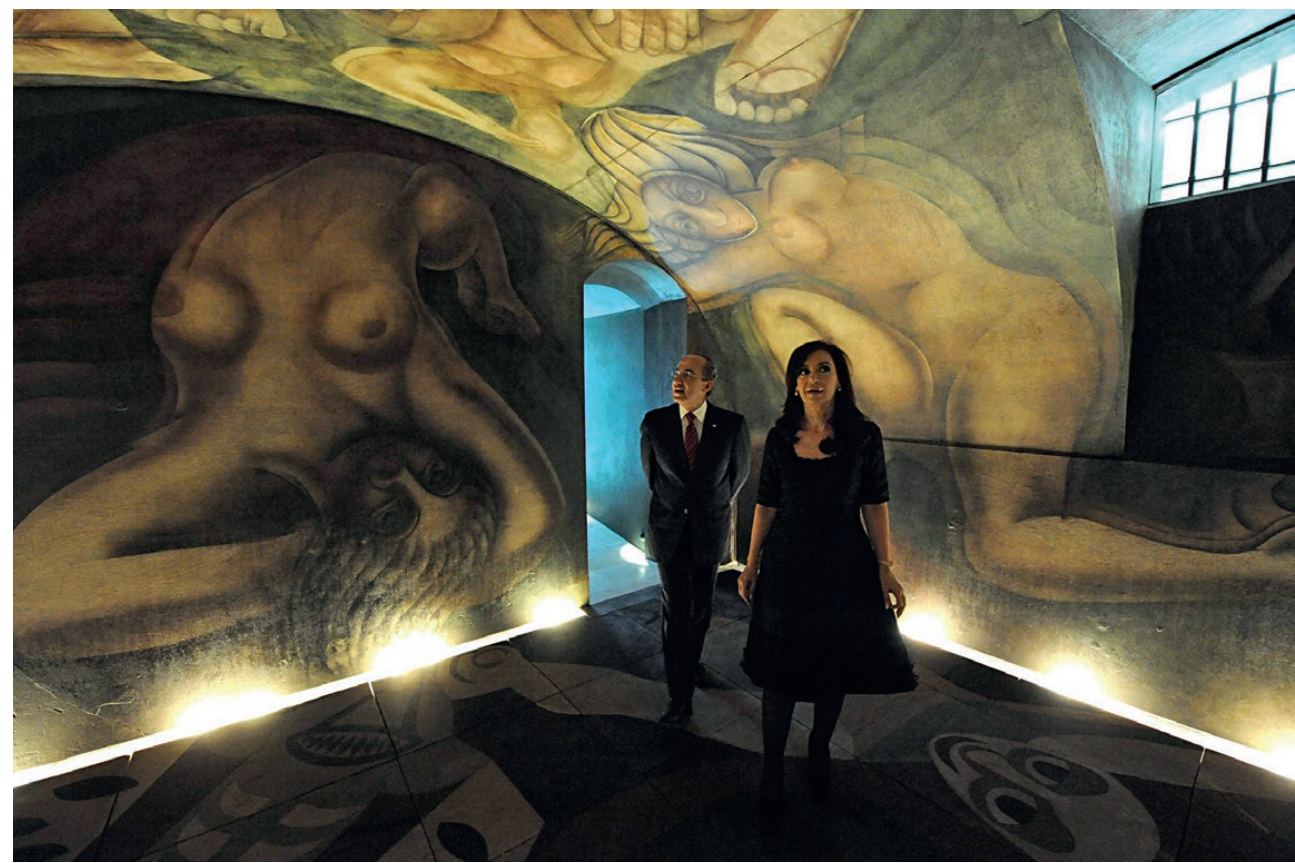

Fig.1. Interior de la cava en la que se encuentra el mural. Fotografía: Diario La Nación. Argentina, 3 de diciembre del 2010.

mecánica, en vez de brocha manual de palo y pelo” (Schávelzon, 2009), como materiales usó el "silicato de etilo, de uso industrial, por su alta resistencia y su protección contra la humedad" y el "proyector de negativos de vidrio" (Schávelzon, 2011:7) para deformar intencionalmente los cuerpos, algo imposible de conseguir con modelos vivos (Schávelzon, 2011:8). Antes de partir de Buenos Aires, a fines de 1933, publicó a nombre de todo el grupo un folleto en el que trataba de justificarse y darle sentido al mural: "La base de eso estaba en el trabajo socializado y en que siguiendo las ideas del cineasta Sergei Eisenstein, lo había hecho para ser filmado y luego proyectado a las masas, lo que justificaba su carácter cerrado. Que en realidad no era un mural pintado a satisfacción de un comitente privado sino un ejercicio para el cine revolucionario" (Schávelzon, 2011:8).

En 1941 Natalio Botana muere, la casa se vende y se inician las peripecias del mural. Los nuevos propietarios consideran "ofensivos los desnudos" e intentan, aunque sin éxito "borrar la obra utilizando ácido, por lo que el Ejercicio plástico fue cubierto con cal”. El siguiente dueño "le quitó la cal y le encargó limpiar el mural a uno de los colaboradores de Siqueiros, Castagnino, quien utilizó aceites que afectaron ligeramente la capa pictórica”. La casa cae en abandono y se transforma en un "albergue de indigentes que hacían fogatas en el invierno, la pieza fue cubierta con grafiti”. Además, la edificación contaba con una serie de daños "el sótano tenía filtraciones y se inundaba en algunas épocas del año", ello es descrito por Héctor Mendizábal, en su libro Ejercicio Plástico, el mural de Siqueiros en la Argentina (Schavelzon, 2009). Héctor Mendizábal, es una pieza clave en la recuperación del mural, al reconocer el valor histórico de la pieza, a fines de la década de los ochenta arma una sociedad para comprar el inmueble y se contacta con el restaurador mexicano Manuel Serrano para iniciar la extracción del mural. La extracción se realiza entre 1989 y 1991, fecha en que es "desmontado en seis partes" y se le guarda en contenedores, con la idea de que permanecería ahí sólo unos meses. No obstante, estuvieron un total de 17 años, con una serie de conflictos, juicios y gastos económicos de por medio (La Nación, 2009). 
Hasta que durante el gobierno de Néstor Kirchner, el 11 de noviembre del 2003 por Decreto 1044/2003, fue declarado bien de interés histórico-artístico nacional (Boletín Oficial de la República Argentina, 2003). Durante la presidencia de Cristina, en octubre de 2008 se inició su restauración y se presentó públicamente en diciembre de 2010, en lo que llegaría a ser el local del Museo Bicentenario, teniendo como invitado de honor a Felipe Calderón Presidente de México (La Nación, 2010).

\section{El Museo de la Casa Rosada}

El Museo del Bicentenario, fue sumamente criticado en cuanto a su contenido, es así que al llegar a la presidencia Mauricio Macri lo cierra para reajustarlo. En junio del 2016 se reabrió con nuevo nombre: Museo de la Casa Rosada. Desde el gobierno se niega que el cambio de nombre se deba a razones políticas antes bien argumentan que la UNESCO recomienda que los "museos de sitio" lleven el nombre del lugar que evocan (Carelli Lynch, 2016). De la antigua administración permaneció el museólogo Juan José Ganduglia como director. Pero, la curaduría de la exhibición cambió y se nombró a Luciano Privitello, investigador del Consejo de Investigaciones Científicas y Tecnológicas, como nuevo director de Programas Culturales. Privitello y Ganduglia trabajaron en el guión museográfico junto con la Asociación Argentina de Investigadores de Historia (ASAIH) y la Academia Nacional de la Historia. Según Privitello "El museo [del Bicentenario] era un horror, tal cual estaba era muy malo". Se refiere al sesgo político partidario que mostraba su guión: "Un museo no puede ser un canto a un gobierno. Lo que tratamos de hacer es hacer un museo con los cánones de un museo". Pone como ejemplo: "el curado de los presidentes se hace alrededor de los 14 arcos que tiene el Museo. En el museo del Bicentenario, la mitad estaban dedicados al peronismo y, dentro de ellos, al gobierno de los Kirchner. Era una celebración del propio gobierno, y eso hacía que la parte de patrimonio del museo no podía ser exhibida, porque del período más actual tiene poco. Este era el principal problema” (Mercado, 2016).

El Museo actualmente está compuesto por tres guiones diferentes dado que tres temas lo integran, señala Privitello: Uno gira alrededor del edificio de la Aduana Taylor, al cual se le ha prestado más atención que antes. El segundo se refiere al Mural de Siqueiros, el cual según Privitello "no tiene mucho que ver con el resto del museo, pero está ahí y no se puede mover”. Y, el tercero, el cual es, según dice: "el más importante, o el que puede generar más polémica, que es el museo de los presidentes", es en ese rubro donde se divisan los mayores cambios (Mercado, 2016). Si bien el Mural no se ajusta a la temática del Museo es poco feliz lo esgrimido como explicación para mantenerlo en el lugar. Lo cierto es que en el contexto poskirchnerista se evidencia en la sociedad argentina una "grieta" (Perfil, s.f) que la divide y que se expresa también en el ámbito cultural malinterpretando las obras utilizadas, o en este caso salvadas del deterioro por el kirchnerismo, como propaganda política. Tal es el caso de la explicación del porqué de la presencia del Mural de Siqueiros en algún sector del periodismo:

Tal vez este estalinismo santacruceño ${ }^{1}$ explique la presencia de un mural de David Siqueiros -pintor mexicano cuyo acto político más destacado fue un intento fallido de asesinar a León Trostky en su exilio en Coyoacán, en 1940, por orden directa de Stalin-, pero lo cierto es que esa obra restaurada es la "pieza central" del "área artística” del Museo Casa Rosada, según la explicación oficial. Cristina Kirchner habla en el Museo. Detrás, la foto del pintor estalinista David Siqueiros, convertido en una suerte de héroe por el revisionismo K. Una restauración muy lograda, dicen los expertos, aunque poco y nada tengan que ver el mural y su autor con la historia institucional argentina (Infobae, 2016).

1 Néstor Kirchner fue Gobernador de Santa Cruz. 


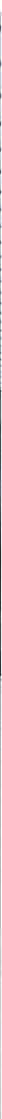

Fig.2. Explanada del museo. Fotografía: Rocío E. Trinidad Zapata.

Ciertamente, el Mural poco tiene que ver con la temática del museo salvo que se busque una interpretación forzada que conecte el espíritu revolucionario de Siqueiros con el sentido revolucionario que pretendía imprimirle el kirchnerismo a su gobierno. Sin embargo, creo que una mirada menos parcializada podría encontrar no sólo valor patrimonial en la pieza, sino que ésta tiene relación con la temática del museo en tanto que es un símbolo de la resiliencia, ha resistido a su destrucción, como lo ha hecho el pueblo argentino a través de la historia. Por otro lado, Ejercicio Plástico es conocido como la única obra no política de Siqueiros, aunque es en sí una revolución en el campo del arte, fue motivado por el apasionamiento entre el artista por su mujer, Blanca Luz Brum²: "La obra, al quedar libre de ataduras formales del Realismo Socialista, se transformó en un canto lírico a su mujer que se separaba de él, en una construcción casi teatral, en una secuencia semi-onírica de una belleza enorme, posiblemente porque desató la capacidad creativa de todo el grupo de artistas" (Schávelzon, 2011:6).

\section{A modo de cierre: la experiencia}

El mural es indudablemente la pieza que más destaca en el museo, no sólo por el lugar central que ocupa, sino porque al ingresar al museo el espectador es confrontado con la

2 Sobre la relación entre David Alfaro Siqueiros y Blanca Luz Brum ver: "El mural de Siqueiros en Buenos Aires (1933): de la ideología al amor, un camino que no tiene regreso" de Daniel Schávelzon CONICET, UBA-Centro de Arqueología Urbana http://www.danielschavelzon.com.ar/ebooks/Siqueiros_Cronicas14.pdf. 


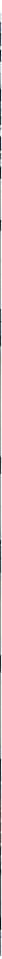

Fig.3. Puerta de ingreso a la cava que contiene el mural. Fotografía: Rocío E. Trinidad Zapata.

foto de un hombre con una mirada imponente y la mano alzada, se trata de un detalle de "Siqueiros tras las rejas", una fotografía de Héctor García. La expectativa generada provoca curiosidad por conocer lo que hay dentro del gran cubo recubierto de fotos en blanco y negro que cuentan la historia de Ejercicio Plástico. Grupos de 15 personas ingresan al cubo, indispensablemente se deben colocar protectores para cubrir los zapatos a fin de que el mural no se contamine y no tomar fotografías. Luego de ello se recibe una charla, de aproximadamente veinte minutos, sobre las circunstancias por las que pasó el mural. Una vez listos empieza la experiencia: se ingresa por una puerta a una especie de nave que lleva por nombre Ejercicio Plástico y que conduce a breve corredor oscuro que lleva a unas escaleras que se dirigen hacia el sótano donde está la cava. El mural fue recuperado completamente e instalado tomando en cuenta las circunstancias originales en las que estaba. Como si se tratara de una gran pecera o una gran burbuja, los personajes desnudos, hombres y mujeres, entre ellos Blanca Luz, también David, nadan o quizá vuelan o se ensimisman en sus remolinos corporales. Una vez ahí, es posible entender el porqué del nombre Ejercicio Plástico, desde donde el espectador se ubique puede ver la pintura en movimiento, envolviéndolo en placer de su dinamismo. Sería mezquino no reconocer el trabajo de la recuperación de la pieza, que hoy está gratuitamente a disposición del público ${ }^{3}$.

3 La experiencia de Alfaro Siqueiros en Argentina y su obra Ejercicio Plástico han sido analizados en documentos escritos sobresaliendo los del citado Daniel Schávelzon, pero también han sido trabajados en documentos audiovisuales de gran calidad, entre ellos figuran: la película México-Argentina El Mural (Héctor Olivera, 2010) y el documental argentino Los Próximos Pasados (Lorena Muñoz, 2006). 


\section{Referencias}

Battistozzi, A. Diario Clarín, (14/4/1997). La exposición de Numa Ayrinhac gira en torno a Perón y Evita. Diario Clarín. Recuperado: http:// edant.clarin.com/diario/1997/04/13/c-01001f. htm (Consulta: 26/10/2016).

Boletín Oficial de la República Argentina. Bienes de Interés Histórico-Artístico Decreto 1045/2003. Recuperado: http://web.archive.org/ web/20121004000733/http://www.diputadoscatamarca.gov.ar/ley/BO2003/BO121103.PDF (Consulta: 27/10/2016).

Carelli Lynch, G. Diario Clarín, (25/06/2016). Macri le cambia el nombre al Museo del Bicentenario. Recuperado: http://www.clarin. com/politica/Macri-cambia-nombre-MuseoBicentenario_0_1601839890.html (Consulta: 27/10/2016).

Casa Rosada. Historia de la Casa Rosada. Recuperado: http://www.casarosada.gob.ar/lacasa-rosada/historia (Consulta 26/10/2016).

García Zúñiga, F. (03/2015). El proyecto del Museo del Bicentenario, Aduana de Taylor, Casa Rosada, Buenos Aires, Argentina. In X Jornada Técnicas de Restauración y Conservación del Patrimonio. p. 5. Recuperado: http://sedici. unlp.edu.ar/handle/10915/44386 (Consulta 26/10/2016).

Infobae, (26/10/2016). Cómo será el museo de la Casa Rosada tras su "normalización". Recuperado: http://www.infobae.com/ politica/2016/06/27/como-sera-el-museo-de-lacasa-rosada-tras-su-normalizacion/ (Consulta: 17/10/2016).

La Nación. (05/06/2009). El mural que vuelve a vivir. Recuperado: http://www.lanacion. com.ar/1142626-el-mural-que-vuelve-a-vivir (Consulta 28/10/2016).
La Nación. (03/12/2010). La Presidenta inauguró el mural de Siqueiros. Recuperado: http:// www.lanacion.com.ar/1330482-la-presidentainauguro-el-mural-de-siqueiros (Consulta 27/110/2016).

Meo Laos, V. (Sin fecha). Asociación Amigos del Arte (1924-1942): Reducto del arte nuevo y activa introductora de las vanguardias. Dossier de trabajos de investigación 1: Nervaduras de la esfera pública. Biblioteca Nacional Mariano Moreno, p. 1. Recuperado: http://www.bn.gov. ar/media/page/asociacion-amigos-del-arte.pdf (Consulta: 27/10/16).

Mercado, S. Infobae, (4/7/2016). Luciano De Privitellio: "Un museo no puede ser un canto a un gobierno". Recuperado: http://www. infobae.com/politica/2016/07/04/luciano-deprivitellio-un-museo-no-puede-ser-un-canto-aun-gobierno/ (Consulta: 27/10/2016).

Perfil. (Sin fecha) Jorge Lanata: "La grieta va a pasar en muchos años porque es cultural". Recuperado: http://www.perfil.com/politica/ jorge-lanata-la-grieta-va-a-pasar-en-muchosanos-porque-es-cultural-1123-0107.phtml (Consulta 27/10/2016).

Schavelzon, D. (2009) Ejercicio Plástico: el mural envolvente de David Alfaro Siqueiros. Artículo publicado en el suplemento la revista Artes de México, número 96, noviembre, pp. 1 - 9, México DF. Recuperado: http://www. danielschavelzon.com.ar/?p=2548 (Consulta: 27/10/2016).

Schávelzon, D. (2011) El mural de Siqueiros en Argentina. Arte y Política en América Latina (1933). Revista Contratiempo. AÑO XI - N 3 / Primavera, p. 5. Recuperado: http://www. revistacontratiempo.com.ar/schavelzon-mural siqueiros.pdf (Consulta: 27/10/16). 